\title{
Development and Application of Integrated Aerodynamic Protuberant Foil Journal and Thrust Bearing in Turboexpander
}

\author{
Tianwei Lai, ${ }^{1,2}$ Yu Guo, ${ }^{1}$ Wei Wang, ${ }^{1}$ Yu Wang, ${ }^{1}$ and Yu Hou ${ }^{1}$ \\ ${ }^{1}$ State Key Laboratory of Multiphase Flow in Power Engineering, Xian Jiaotong University, Xi'an 710049, China \\ ${ }^{2}$ Xian Jiaotong University Suzhou Institute, Suzhou 215123, China \\ Correspondence should be addressed to Yu Hou; yuhou@mail.xjtu.edu.cn
}

Received 23 August 2017; Revised 1 December 2017; Accepted 17 December 2017; Published 31 December 2017

Academic Editor: Lei Tan

Copyright (c) 2017 Tianwei Lai et al. This is an open access article distributed under the Creative Commons Attribution License, which permits unrestricted use, distribution, and reproduction in any medium, provided the original work is properly cited.

\begin{abstract}
Foil bearing provides compliant support and moderate Coulomb friction for rotor-bearing system, which is conducive to stability and reliability of high speed rotating machinery. In this paper, both hydrodynamic lubricated foil journal and foil thrust bearings are applied in a $150 \mathrm{~m}^{3} \cdot \mathrm{h}^{-1}$ turboexpander for air separation. In the bearings, protuberant foil is chosen as the supporting subfoil due to its merits of easy fabrication and assembly. Static loading and deflection of the bearings are tested, respectively, before integration into the turboexpander. Afterwards, the loading and deflection curves of the journal and thrust bearings are polynomial fitted using least-square method. Then, performance tests are carried out on the rotor-bearing system, including transient speed-up, high speed, and speed-down processes. In the tests, the turboexpander supported by the hydrodynamic foil bearings operates smoothly with repeatability. Maximal rotor speed of the turboexpander reaches $52000 \mathrm{rpm}$ with hydrodynamic lubricated protuberant foil bearings.
\end{abstract}

\section{Introduction}

Turboexpander is an indispensable component in energy conversion system. Higher speed is anticipated for the turboexpander in pursuit of high efficiency [1]. Its smooth operation depends, to a large extent, on the stability of the rotor-bearing system. In high speed or oil-free occasions, conventional oil lubrication is constrained due to its high viscosity and contamination issues [2]. Gas foil bearing, as an alternative, is a kind of gas bearing using pieces of metal foil as support. It is outperformed for high speed [3], higher reliability [4], soft failure [5], and extreme temperature adaptability $[6,7]$, as well as high levels of misalignment tolerance [8]. Additionally, aerodynamic lubrication using process gas in high speed operation is in favor of system conciseness and compactness.

For the foil bearing, multikinds of underlying supporting configurations have been developed since its first debut [9]. Among them, bump type foil bearing attracted considerable attention [10]. Besides, metal mesh [11] and viscoelastic $[12,13]$ configurations and so on have been presented. Foil bearing reduces the peak vibration amplitude notably when the rotor crosses the critical speed [14, 15]. Schiffmann and Spakovszky optimized the selective shimming in foil bearing and proposed a design guideline [4]. Pham and Ahn combined foil bearing and magnetic bearing to support a flexible rotor with vibration reduction of $26 \%$ [16].

In foil bearing, compliant surface and nonlinear friction are introduced due to the configuration of stacking foils. With the same load distribution, various foil deflections might be present that is ascribed to the hysteretic behavior of the friction force [17]. Subfoil stiffness of the elastic support affects the bearing load capacity [18]. The ultimate load of the bearing could not exceed that of underlying elastic structure [3].

For decades of development, foil bearing was applied in many high speed rotating machineries [19]. Lee et al. applied foil thrust bearing in automotive turbochargers with $24 \mathrm{~mm}$ diameter shaft at speed of $123000 \mathrm{rpm}$ (round per minute) [20]. Dykas et al. adopted foil thrust bearing in micro turbomachinery with inner diameter of $50.8 \mathrm{~mm}$ and outer diameter of $101.6 \mathrm{~mm}$ with load capacity of $125 \mathrm{~N}$ 
around $23000 \mathrm{rpm}$ [21]. Kim et al. evaluated the foil bearing performance in a $120 \mathrm{~kW}$ gas turbine generator with rated speed of $15800 \mathrm{rpm}$ and generator weight of $84.2 \mathrm{~N}$ and turbine weight of $175.0 \mathrm{~N}$ [22]. Kim et al. applied foil thrust bearing and journal bearing in a $66 \mathrm{~mm}$ diameter $75 \mathrm{~kW}$ turbo blower with rotor speed of $30000 \mathrm{rpm}$, and subsynchronous rotor lateral motions appeared [23]. Kim et al. designed the mesoscale foil gas bearing for palm-sized turbomachinery with inner diameter of $5 \mathrm{~mm}$ and designed speed of $60000 \mathrm{rpm}$ [24].

Comparing to existing hydrostatic bearing technology in cryogenic turboexpander, its configuration can be simplified to a large extent using hydrodynamic lubricated foil bearing. Two kinds of journal bearings, copper wire support and viscoelastic support, were compared for small cryogenic turboexpander of $12 \mathrm{~mm}$ diameter around $220000 \mathrm{rpm}$ [6]. Recently, bump foil journal bearings was applied in the above turboexpander that could operate smoothly in a wide speed range [25]. Numerical results indicated that the journal bearing was stable in high speed range [26]. Subsynchronous vibrations were suppressed quite well [27,28]. Static structure stiffness and load capacities of the thrust bearing were tested in transient start-up and speed-down processes [29, 30]. Dedicated tests on protuberant foil journal bearing or thrust bearing were conducted, respectively. However, hydrodynamic lubrication using both protuberant foil journal and thrust bearings (integrated aerodynamic foil bearing supporting technology) in the turboexpander has not been tested yet. In this paper, both protuberant foil journal bearing and foil thrust bearing are applied in a turboexpander with shaft diameter of $25 \mathrm{~mm}$ for air separation. In the bearings, protuberant foil is chosen as the supporting subfoils due to its merits of easy fabrication and assembly. Experimental tests are carried out to analyze the transient performance of the integrated aerodynamic foil bearing supporting technology. In addition, static loading and unloading of the foil journal bearing and thrust bearing are tested.

\section{High Speed Turboexpander}

The retrofitted turboexpander in this paper, as shown in Figure 1, is an existing commercial module with liquid nitrogen production of $30 \mathrm{~L} \cdot \mathrm{h}^{-1}$. The turbine type expansion wheel converts high pressure gas into low pressure and low temperature states. Braking wheel is used to dissipate the power retrieved from the coaxial expansion wheel.

Rotor-bearing system of the turboexpander is shown in Figure 2. The rotor is horizontal layout and its weight is supported by two journal bearings. The net axial load from expansion wheel and braking wheel is balanced by two thrust bearings. Some geometrical parameters of the turboexpander are listed in Table 1. The former bearing supporting technology of the turboexpander is based on aerostatic journal and thrust bearing. The rated operating speed of the turboexpander is $100000 \mathrm{rpm}$.

\section{Test Rig}

In order to validate the applicability of integrated aerodynamic foil bearing supporting technology in this

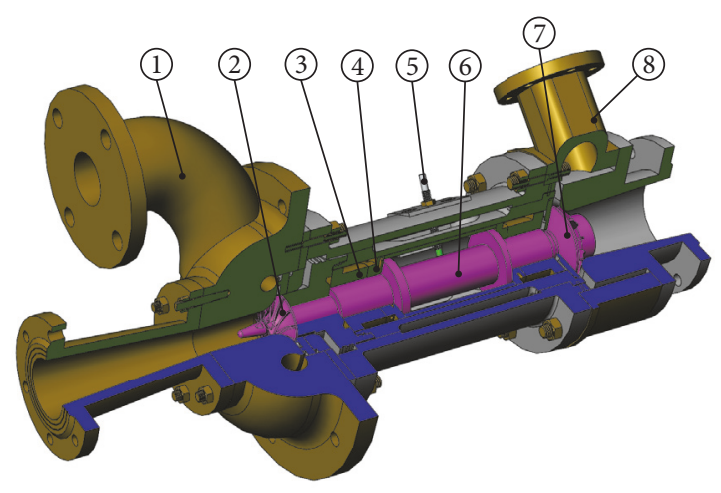
(1) Expansion volute
(5) Displacement transducer
(2) Expansion wheel
(6) Shaft
(3) Journal bearing
(7) Braking wheel
(4) Thrust bearing
(8) Braking volute

FIGURE 1: Assembly drawing of turboexpander for $150 \mathrm{~m}^{3} \cdot \mathrm{h}^{-1}$ air separation system.

TABLE 1: Geometrical parameters of the turbo-expander.

\begin{tabular}{lc}
\hline Parameter & Magnitude \\
\hline Diameter of braking wheel $(\mathrm{mm})$ & 60 \\
Diameter of expansion wheel $(\mathrm{mm})$ & 36.5 \\
Outer diameter of thrust disc $(\mathrm{mm})$ & 44 \\
Distance between journal bearings $(\mathrm{mm})$ & 127 \\
Aspect ratio of journal bearing & $\approx 1$ \\
Diameter of shaft $(\mathrm{mm})$ & 25 \\
Length of rotor $(\mathrm{mm})$ & 250.5 \\
Density of shaft $\left(\mathrm{kg} \cdot \mathrm{m}^{-3}\right)$ & 7830 \\
Density of wheels $\left(\mathrm{kg} \cdot \mathrm{m}^{-3}\right)$ & 2730 \\
Weight of rotor $(\mathrm{g})$ & 891 \\
\hline
\end{tabular}

turboexpander, the test rig of high speed turboexpander is retrofitted based on the rig in reference [31]. The flow chart of gas driven test rig is shown in Figure 3. Compared to the aerostatic bearing supported turboexpander, there is no extra dedicated gas circuit for aerostatic bearings. Therefore, the system is simplified for lighter weight and compactness. High pressure air is supplied by a $75 \mathrm{~kW}$ screw compressor with maximal pressure of $1.0 \mathrm{MPa}$ and maximal flow rate of $600 \mathrm{Nm}^{3} \cdot \mathrm{h}^{-1}$. Gas reservoir is implemented to stabilize the undulating pressurized gas from the compressor. Supply gas pressure and flow rate at the expansion wheel are regulated by proportional electric valve. The exhaust gas is vent to the ambient after expansion. Three eddy current displacement transducers (with linearity of $< \pm 2 \%$ and static resolution of $0.1 \mu \mathrm{m})$ in $X, Y$, and $Z$ directions are installed to evaluate the vibrations of the high speed rotor. Sampling frequency of the displacement transducer is $100 \mathrm{kHz}$. The vibration data are collected by data acquisition system. Supply pressure is measured by pressure transducer (with resolution of $1000 \mathrm{~Pa}$ and $\mathrm{FS} \pm 1 \%$ ).

The real picture of the test rig is shown in Figure 4 (expansion volute was removed from the turboexpander). The vibration transducers are installed as shown in the figure. 


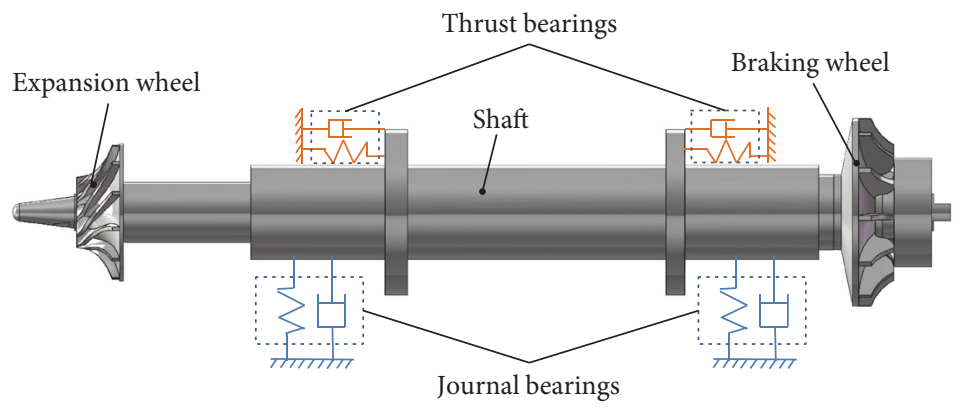

FIGURE 2: Rotor-bearing system of the turboexpander.

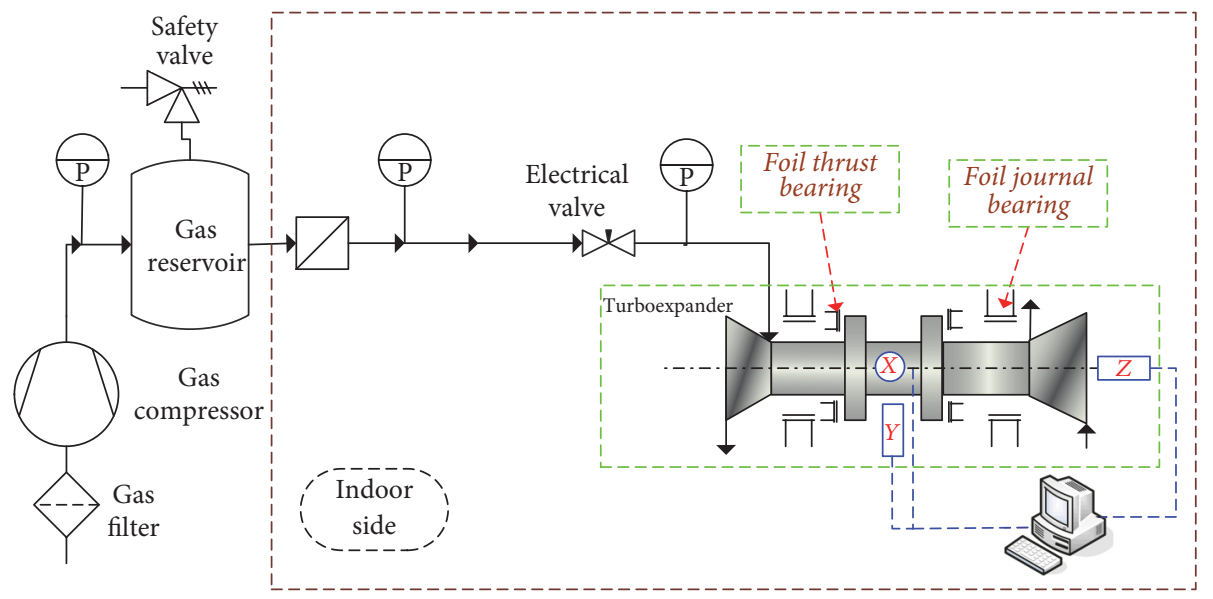

FIGURE 3: Flow chart of high pressure gas driven turboexpander test rig.

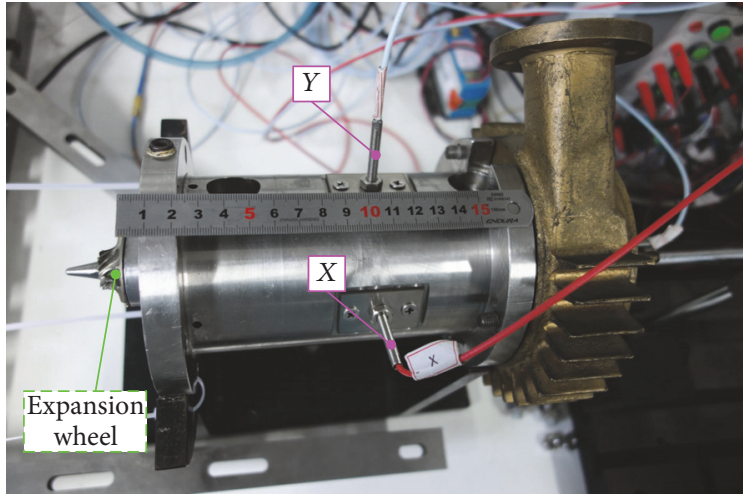

(a)

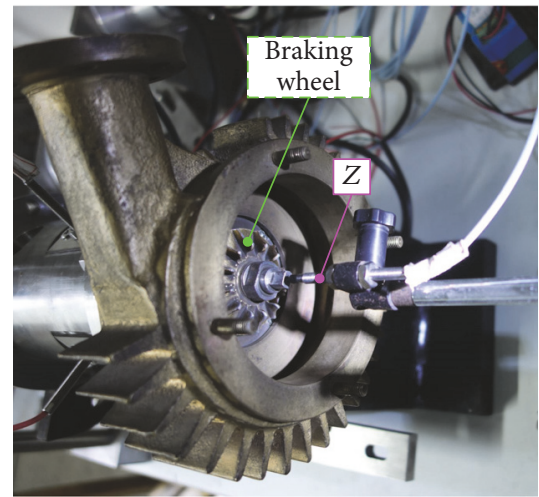

(b)

FIGURE 4: Real picture of high pressure gas driven turboexpander test rig: (a) upper view; (b) side view (with expansion volute removed).

\section{Bearing Configurations}

In pursuit of stability and compactness of turboexpander, aerodynamic foil bearing is a preferred choice. By virtue of the transient performances of the protuberant foil journal and thrust bearings [27-30], they are considered to be alternative candidates for the rotor-bearing system. In this paper, both the aerostatic journal and thrust bearings are replaced by protuberant foil bearings based on the previous configuration of the rotor-bearing system.
The schematic diagram and real picture of the protuberant foil journal bearing are shown in Figures 5(a) and 5(b), respectively. There are two protuberant foil layers and one top flat foil that stacked one layer over another in the bearing housing. The foils are fixed into the housing at one end by fixing pin. The detailed geometrical parameters and stacking layout of the foils could be found in Table 2 .

Before application of the journal bearing and thrust bearing, deflection of the journal bearing and thrust bearing 


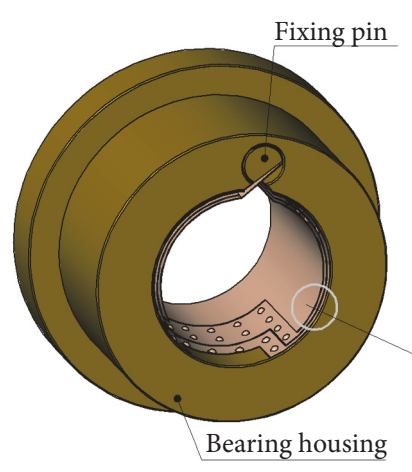

(a)

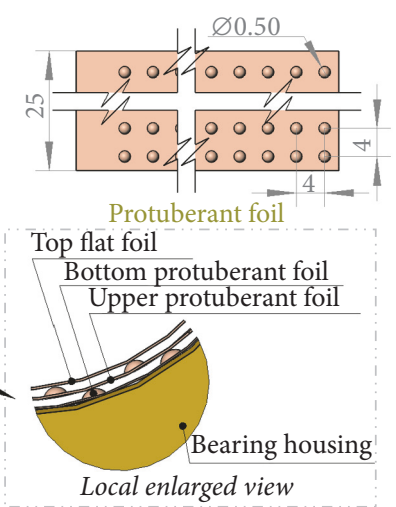

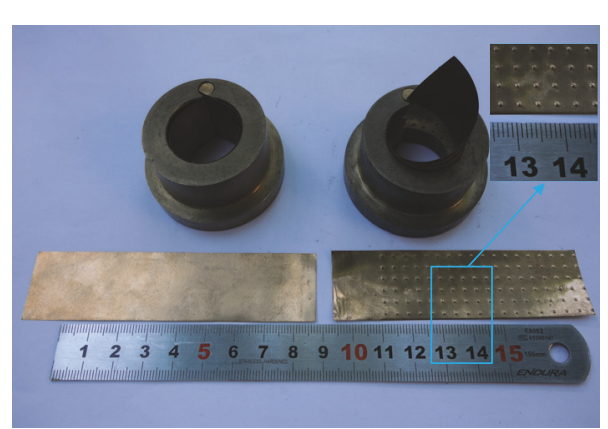

(b)

FIGURE 5: Schematic diagram and real picture of foil journal bearing in the turboexpander.

TABLE 2: Geometrical parameters of the protuberant foil journal bearing [31].

\begin{tabular}{lc}
\hline Parameter & Magnitude \\
\hline Nominal $G_{\mathrm{m}} / \mathrm{g}$ & 830 \\
Height of protuberant foil $H_{\mathrm{p}} / \mathrm{mm}$ & 0.2 \\
Crown pitch in peripheral direction of upper layer & 4 \\
$S_{\mathrm{pu}} / \mathrm{mm}$ & \\
Crown pitch in peripheral direction of lower layer & 4 \\
$S_{\mathrm{au}} / \mathrm{mm}$ & 0.05 \\
Protuberant foil thickness $T_{\mathrm{p}} / \mathrm{mm}$ & 0.07 \\
Top foil thickness $T_{\mathrm{f}} / \mathrm{mm}$ & 4 \\
Crown pitch in peripheral direction of upper layer & 4 \\
$S_{\mathrm{pb}} / \mathrm{mm}$ & 4 \\
Crown pitch in peripheral direction of lower layer & \\
$S_{\mathrm{ab}} / \mathrm{mm}$ &
\end{tabular}

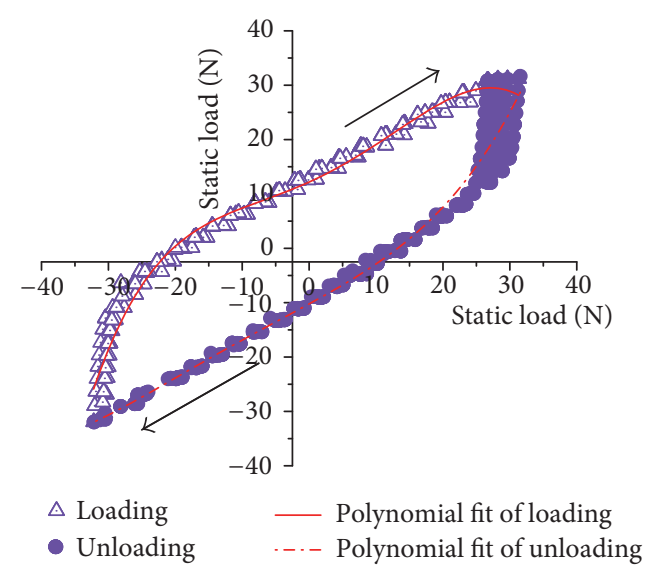

FIgURE 6: Deflection of protuberant foil journal bearing with static load.

under static load are performed on respective dedicated bearing test rigs.

Static load and deflection of the journal bearing is shown in Figure 6. In mild load range from $-25 \mathrm{~N}$ to $+25 \mathrm{~N}$, the
TABLE 3: Standard error of the polynomials for load and deflection curves of journal bearing.

\begin{tabular}{lcc}
\hline Coefficients of the polynomials & Loading & Unloading \\
\hline Interception & 0.233 & 0.1963 \\
$x$ & 0.0172 & 0.0146 \\
$x^{2}$ & 0.00138 & 0.00117 \\
$x^{3}$ & $2.61 E-05$ & $2.42 E-05$ \\
$x^{4}$ & $1.53 E-06$ & $1.32 E-06$ \\
\hline
\end{tabular}

load and displacement exhibits linear relationship. Nonlinear characteristics appears in higher load range from $+30 \mathrm{~N}$ to $+25 \mathrm{~N}$ and from $-30 \mathrm{~N}$ to $-25 \mathrm{~N}$. The displacement is about $30 \mu \mathrm{m}$ at the maximal load of $\pm 30 \mathrm{~N}$. Under the same load, the absolute static deflection is higher in unloading process than that in loading process. For example, the displacement is about $10 \mu \mathrm{m}$ when the static load is $0 \mathrm{~N}$ in the loading process. With the same load in unloading process, the displacement is about $-20 \mu \mathrm{m}$, which is larger than that in loading process. This can be attributed to the hysteresis effect from Coulomb friction in loading and unloading processes. The area enclosed in hysteresis loop can be used to calculate the dissipated energy in one loading test cycle. Fourth-order polynomial was used to fit the loading curves based on weighted least-square method. The polynomial expressions for the loading and unloading processes for beryllium bronze bearing are shown in (1) and (2), respectively. The standard errors of the polynomials are listed in Table 3 . The coefficients of displacement $x$ are $0.67 \mathrm{~N} \cdot \mu \mathrm{m}^{-1}$ in the loading process, which is higher than that in the unloading process of $0.55 \mathrm{~N} \cdot \mu \mathrm{m}^{-1}$ from

$$
\begin{aligned}
y_{\text {loading }}= & -10.2+0.67 x+0.0028 x^{2}+0.00029 x^{3} \\
& +0.000006 x^{4} \\
y_{\text {unloading }}= & 12.2+0.55 x+0.0013 x^{2}+0.00026 x^{3} \\
& +0.000023 x^{4} .
\end{aligned}
$$




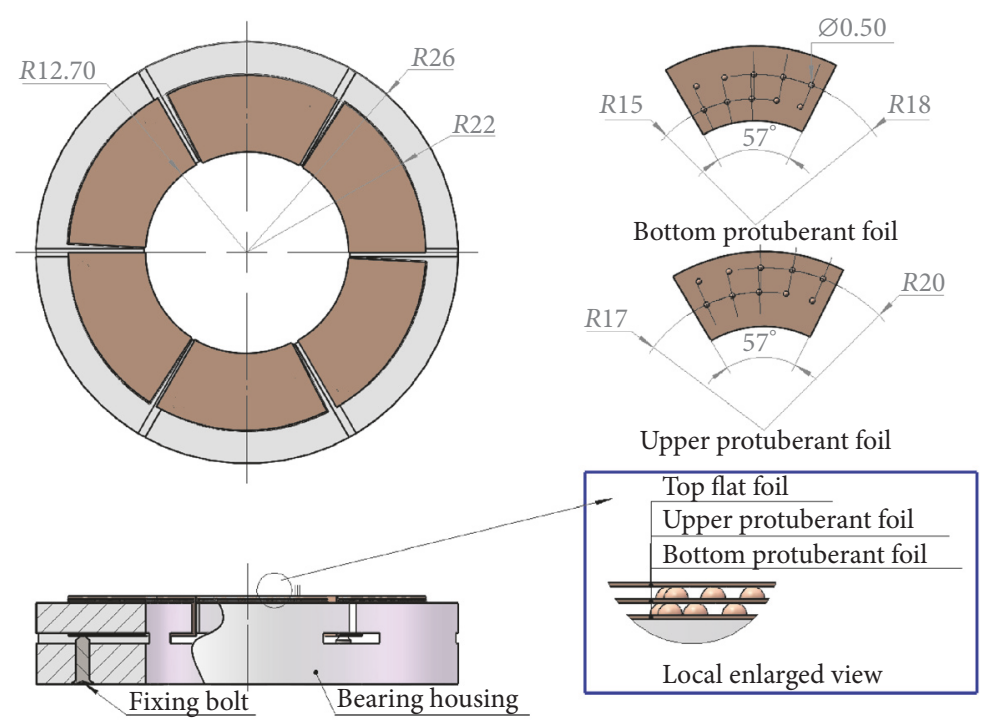

(a)

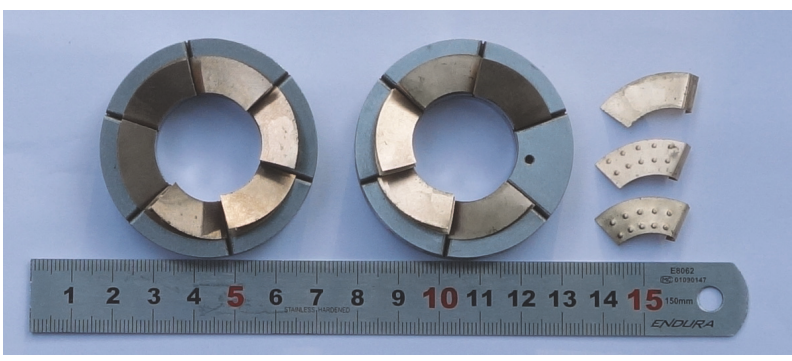

(b)

FIGURE 7: (a) Schematic diagram and (b) real picture of foil thrust bearing in the turboexpander.

TABLE 4: Geometrical parameters of the protuberant foil thrust bearing [32].

Parameter Magnitude

Top foil thickness $t_{\mathrm{tf}} / \mathrm{mm}$

Protuberant foil thickness $t_{\mathrm{pf}} / \mathrm{mm}$

Number of supporting layers $N_{l}$

Height of protuberant convex $h_{\mathrm{pf}} / \mathrm{mm}$

Spherical radius of projections $R_{\mathrm{sp}} / \mathrm{mm}$

Radial location of inner protuberant projections $R_{\mathrm{pi}} / \mathrm{mm}$

Upper layer

According to the existing configuration of shaft and journal bearing, two thrust bearings are implemented to balance the axial forces from the wheels. In the foil thrust bearing, as is shown in Figure 7, six-pad configuration is adopted due to its preferable loading performance [32]. The configuration of the foil stacking is similar to the journal bearing above; detailed parameters of the thrust bearing can be found in Table 4. Protuberant projections of diameter of $0.5 \mathrm{~mm}$ on the foils are punched from flat foil. The stacking layout of upper protuberant foil and bottom protuberant foil is staggered in circumferential direction according to the locations of the supporting projections. The foils are fixed by screw bolt from the back of thrust bearing.

The deflection of the thrust bearing with static load is shown in Figure 8. Detailed testing method can refer to [33]. Unlike the protuberant foil journal bearing, the hysteresis loop of the deflection of the thrust bearing is smaller. Structural stiffness of six-pad multilayer protuberant foil thrust bearing is not constant and load dependent. The polynomial expressions for the loading and unloading 


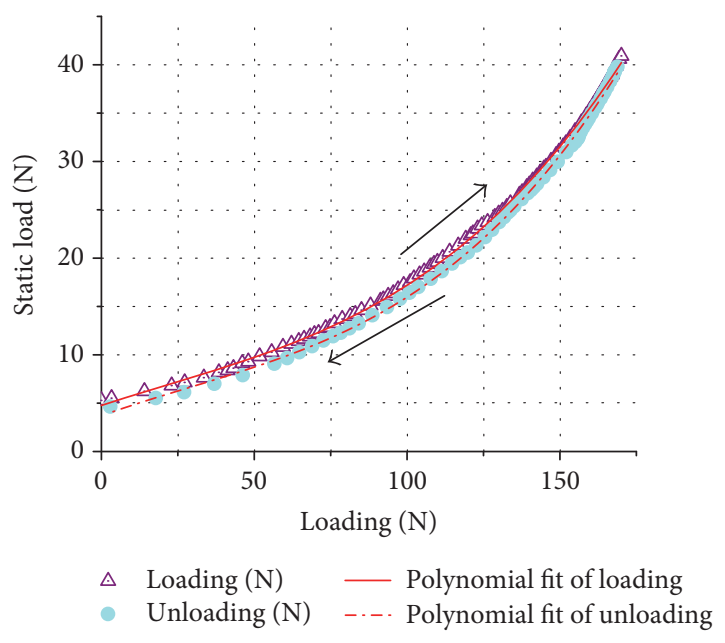

FIGURE 8: Deflection of protuberant foil thrust bearing with static load.

TABLE 5: Standard error of the polynomials for load and deflection curves of thrust bearing.

\begin{tabular}{lcc}
\hline Coefficients of the polynomials & Loading & Unloading \\
\hline Interception & 0.259 & 0.178 \\
$x$ & 0.0114 & 0.00736 \\
$x^{2}$ & $1.39 E-04$ & $9.05 E-05$ \\
$x^{3}$ & $4.91 E-07$ & $3.26 E-07$ \\
\hline
\end{tabular}

processes for beryllium bronze bearing are shown in (3) and (4), respectively. The standard errors of the polynomials are listed in Table 5.

$$
\begin{aligned}
y_{\text {loading }}= & -4.76+0.104 x-3.85 x^{2}+0.00000587 x^{3}, \\
y_{\text {unloading }}= & 3.70+0.113 x+0.000598 x^{2} \\
& +0.00000695 x^{3} .
\end{aligned}
$$

\section{Testing Procedures}

The testing process is shown in Figure 9. After checking the preparation for ready to start up, open up the electrical valve of supply gas at the expansion wheel gradually. The gas pressure increment should be small until the rotor started to rotate. Maintain the supply pressure to be constant when the rotor is in acceleration. Afterwards, increase the gas supply pressure further until the rotor speed is around $50000 \mathrm{rpm}$. After smooth operating for a period of time, close down the supply gas gradually to reduce the rotor speed. When the rotor stops operating, close the supplying gas valve. More than three times of start-up and speed-down processes are conducted to ensure the repeatability of collected data.

\section{Test Results and Analysis}

For this integrated bearing layout, there exist friction torques from the journal bearing and the thrust bearing, especially during the start-up process. When the preload on the thrust

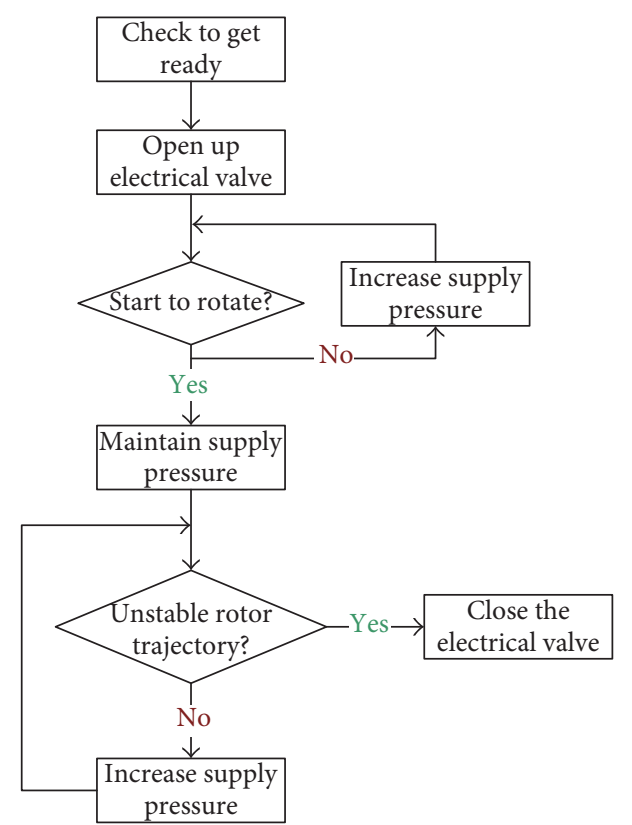

FIgURE 9: Testing process of the turboexpander with protuberant foil journal and thrust bearing.

bearing is larger than a certain value, the torque at expansion wheel could not overcome the start-up friction torque [34]. Furthermore, during start-up and speed-down transient processes, friction torque of the foil thrust bearing increases linearly with rotor speed and bearing load. Therefore, the conventional start-up method of rotor by increasing the supply pressure does not fit for the integrated foil bearing supporting technology. In order to reduce the friction torque at the start-up stage, the nominal journal bearing clearance is increased to $100 \mu \mathrm{m}$.

Transient processes such as start-up, high speed, and speed-down of the rotor supported by integrated foil journal bearing and thrust bearing are tested after assembly of the turboexpander. In the transient processes, axial displacement is an important indicator of axial movement of the rotor due to net axial force from expansion wheel and braking wheel. Rotor speed and axial displacement of the rotor with supply pressure in the whole speed-up and speed-down processes are shown in Figure 10. At the beginning $8 \mathrm{~s}$, there is no supply pressure. From $8 \mathrm{~s}$ to $18 \mathrm{~s}$ in region I, in which the supply pressure increases to around $0.13 \mathrm{MPa}$, there is no rotation yet due to the static friction between the rotor and foil surfaces. Because of the pressure difference between the front and back of expansion wheel, the rotor moves in the direction of expansion wheel with displacement around $180 \mu \mathrm{m}$ before rotation. In region $\mathrm{II}$, when the supply pressure exceeds $0.13 \mathrm{MPa}$, the rotor begins to rotate. The supply pressure is maintained at this value when the rotor is in accelerating process. In this region, the aerodynamic lubrication comes into effect due to the relative speed between the rotor and bearing surface. The hydrodynamic lubrication force pushes the rotor towards the braking wheel. Therefore, the thrust bearing clearance increases during this speed-up process. In region III, the 


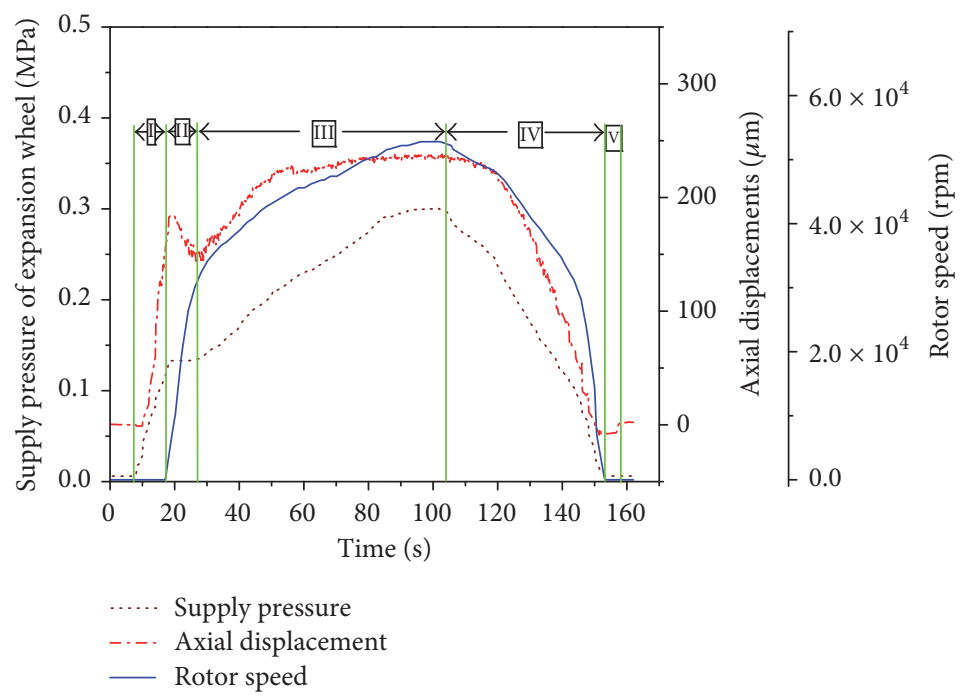

Figure 10: Axial displacement of the rotor in transient processes.

supply pressure increases further with expectation of higher rotor speed. The axial force from the wheels increases and the rotor moves axially in the direction of expansion wheel again. The axial displacement increases to $230 \mu \mathrm{m}$ when higher supplying pressure is supplied continuously. The rotor speed reaches $52805 \mathrm{rpm}$ with supply pressure of $0.3 \mathrm{MPa}$. Afterwards, the rotor speed is reduced gradually in region IV. In the speed-down process, the axial displacement of the rotor decreases correspondingly. It should be noted that there is minus axial displacement at the end of speed-down process. Furthermore, there are still minus axial displacements after the rotor stops running in region V. Recovery time of axial displacement is needed after one speed-up and coast-down process, which can be attributed to the hysteresis effect of the foils in the whole operating region. During the transient processes, the displacement is positive in most of the regions. That is to say, most of the axial force is balanced by the thrust bearing near expansion wheel.

During the transient operation, high speed rotor vibrates around its transient equilibrium position. The journal centerline during the above transient processes is shown in Figure 11. The rotor rotates in counterclockwise direction in the bearing. The circumferential angle $\theta$ initiates from upright direction of the bearing. Journal center location reflects its eccentricity and attitude angle $\left(\theta-270^{\circ}\right)$. The journal center in speed-up process is marked by red hollow rectangles and speed-down process is marked by blue hollow circles. The initial static resting position of the rotor is assumed to be (100, $270^{\circ}$ ) in above polar coordinates. At lower speed before liftoff from the foil bearing, the rotor lifts up about $6 \mu \mathrm{m}$ towards the bearing center and $9^{\circ}$ in counterclockwise direction. At the speed around $9600 \mathrm{rpm}$, the journal center drifts about $5 \mu \mathrm{m}$ towards the bearing center and $10^{\circ}$ in counterclockwise direction that is marked as the lift-off speed of the bearing during the built-up of the aerodynamic film. The eccentricity and attitude angle of the rotor are $91 \mu \mathrm{m}$ and $19^{\circ}$, respectively. The lift-off speed is around $9600 \mathrm{rpm}$. After lift-off from the

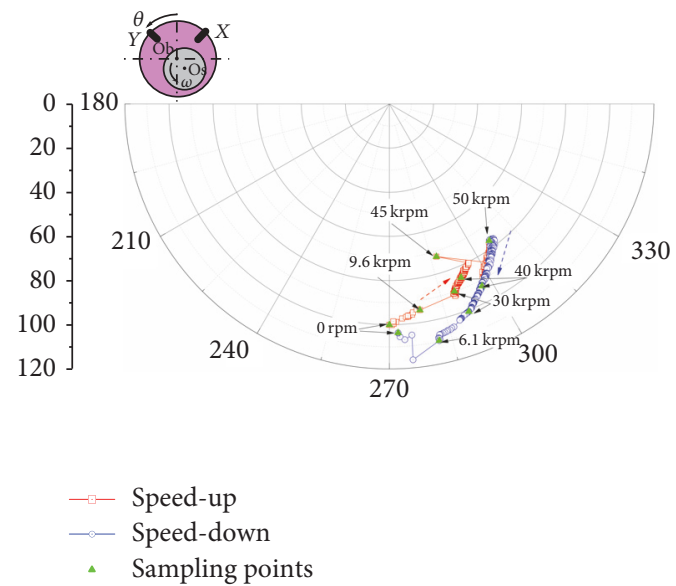

FIgURE 11: Polar plot of journal during the transient start-up and coast-down processes.

bearing, the rotor centerline moves smoothly from $9600 \mathrm{rpm}$ to $30000 \mathrm{rpm}$. At around $45000 \mathrm{rpm}$, another unexpectedly rotor drift is observed. The eccentricity increases from $81 \mu \mathrm{m}$ to around $89 \mu \mathrm{m}$ and attitude angle undulates about $10^{\circ}$. This might be attributed to force and pressure undulation in the high speed rotating machinery [35-39]. Then the rotor drifts up $15 \mu \mathrm{m}$ with increase of rotor speed. After the rotor reaches maximal speed of $52800 \mathrm{rpm}$, the speed-up process is terminated in avoidance of instability or bearing failure. Then, speed-down process commences. In the speed-down process, the rotor slides down in the bearing almost continuously from $\left(77,306^{\circ}\right)$ to $\left(110,282^{\circ}\right)$. Then the rotor touches down on the foil bearing at about $6100 \mathrm{rpm}$. Generally, the rotor location in the speed-down process is lower comparing to those in the speed-up process at the same rotor speed. For example, at the same rotor speed of $30000 \mathrm{rpm}$, the rotor centerline is at $(90$, $\left.290^{\circ}\right)$ in speed-up process and is at $\left(100,290^{\circ}\right)$ in speed-down 


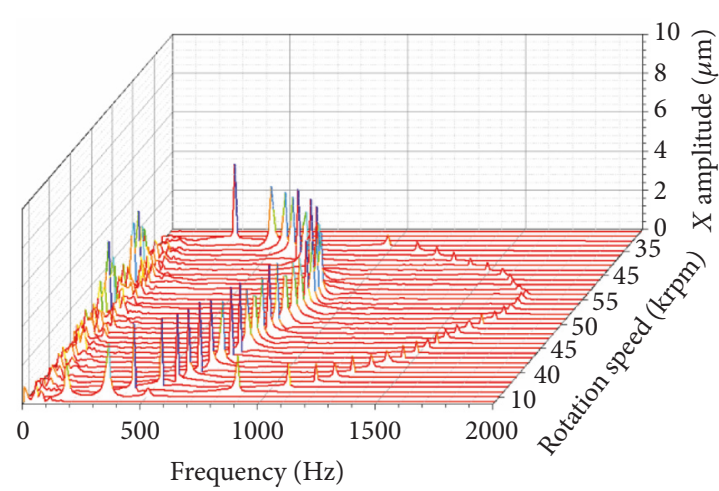

(a)

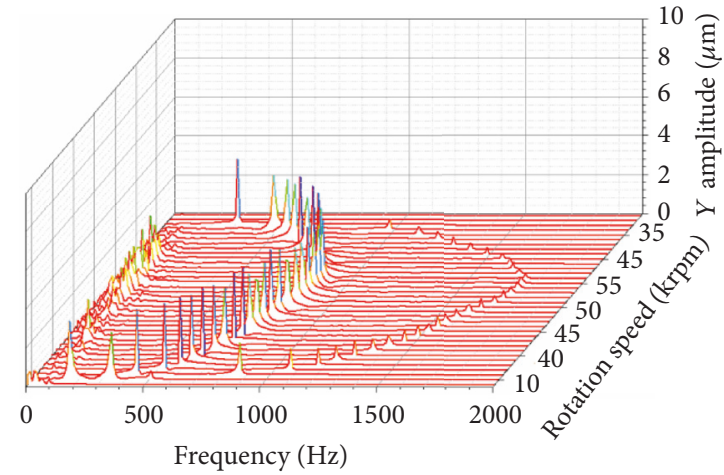

(b)

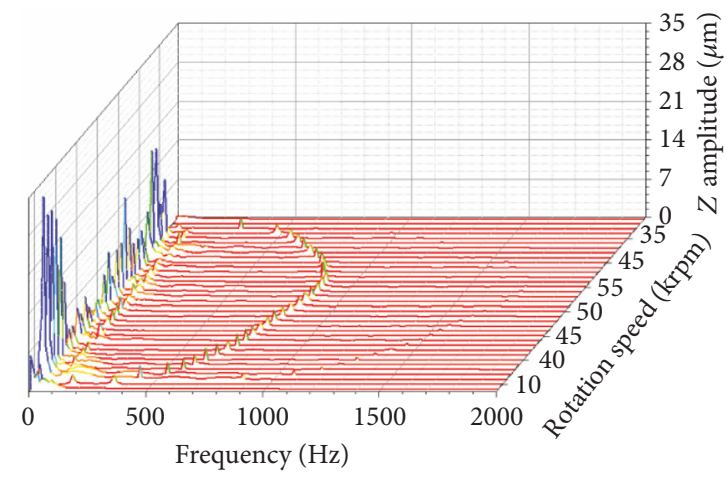

(c)

FIGURE 12: Spectrum cascade plot of the high speed rotor in the speed-up and coast-down process: (a) $X$ direction; (b) $Y$ direction; (c) $Z$ direction.

process. When the rotor speed is smaller than $30000 \mathrm{rpm}$, it should also be noted that the eccentricity exceeds the nominal bearing clearance of $100 \mu \mathrm{m}$ in the speed-down process. Indeed, the foil bearing could provide over-nominal bearing clearance with compliant surface. The landing speed of the rotor on the foil bearing is around $6000 \mathrm{rpm}$, which is smaller than that of lift-off speed of $9600 \mathrm{rpm}$. This can be attributed to the friction effect between the foils during the speed-up and speed-down processes [31]. The resting location of the rotor after coast-down is $\left(103,272^{\circ}\right)$. Similar to the thrust bearing above, this might also be attributed to the static friction and hysteresis effect of the foils in the above speed-up and speed-down processes.

In this test, the rotor vibrations in $X, Y$, and $Z$ directions are transformed into frequency domain by FFT. The FFT spectrum cascade plots of the vibrations are shown in Figures $12(\mathrm{a}), 12(\mathrm{~b})$, and $12(\mathrm{c})$, respectively. The main frequencies $(1 \mathrm{~N})$ of the rotor are obvious comparing to other components. In all three directions, there are nonsynchronous vibrations around $100 \mathrm{~Hz}$. In radial directions $X$ and $Y$, the nonsynchronous vibration amplitudes are larger comparing to the cascade plot of the rotor supported with foil journal bearing and aerostatic thrust bearing in reference [31]. When the rotor speed is larger than $50000 \mathrm{rpm}$, the nonsynchronous vibration amplitude increases and exhibits speed dependency. These could be attributed to the introduction of six-pad protuberant foil thrust bearing and loose journal bearing preload. In higher speed range $4000 \mathrm{rpm} \sim 5000 \mathrm{rpm}$, the vibration amplitude in $X$ direction is about $3 \mu \mathrm{m}$ that is higher than that of $<2 \mu \mathrm{m}$ in $Y$ direction, which can be attributed to higher attitude angle. In axial $Z$ direction, the vibration amplitude of main frequency $(1 \mathrm{~N})$ is around $2 \mu \mathrm{m}$. In smaller speed range, the vibration amplitude at low frequencies $(20 \sim 30 \mathrm{~Hz})$ is obvious larger. It reaches $30 \mu \mathrm{m}$ around $30 \mathrm{~Hz}$ at the initial start-up stage. This might be attributed to configuration and assembly of the foil thrust bearing. With increase of supply gas pressure and the aerodynamic effect from braking wheel, the vibrations at low frequencies $(20 \sim 30 \mathrm{~Hz})$ are suppressed at higher rotor speed.

In order to get a clearer view of the transient processes, vibration amplitudes at main frequencies (1N) are extracted from the FFT cascade plot. The vibration amplitude at main frequencies in $X, Y$, and $Z$ directions are shown in Figures 13(a), 13(b), and 13(c), respectively. When the rotor speed is lower than $10000 \mathrm{rpm}$ before lift-off, there are critical speeds around $3700 \mathrm{rpm}$ and $7200 \mathrm{rpm}$. For these lower order critical speeds, there is not much difference between the speed-up and speed-down processes. These two lower order critical speeds appear in all three directions. However, there are obvious differences in higher order critical speeds. For instance, the third critical speed is around $12000 \mathrm{rpm}$ in the speed-up process and $17000 \mathrm{rpm}$ in the speed-down process. The forth critical speed is around $21000 \mathrm{rpm}$ in the speedup process and $25000 \mathrm{rpm}$ in the speed-down process. In 


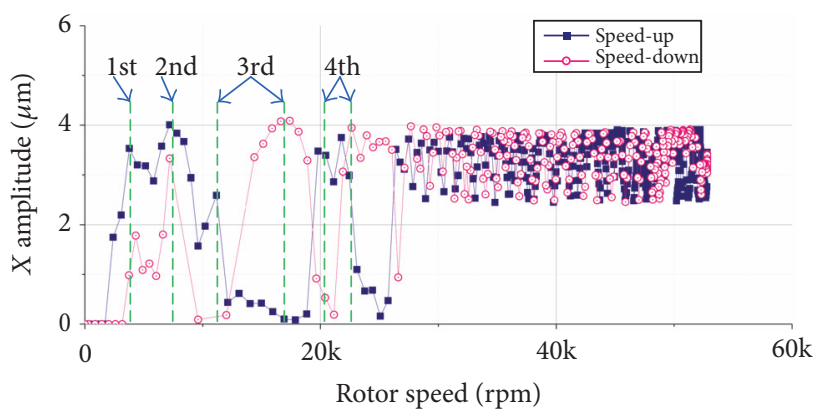

(a)

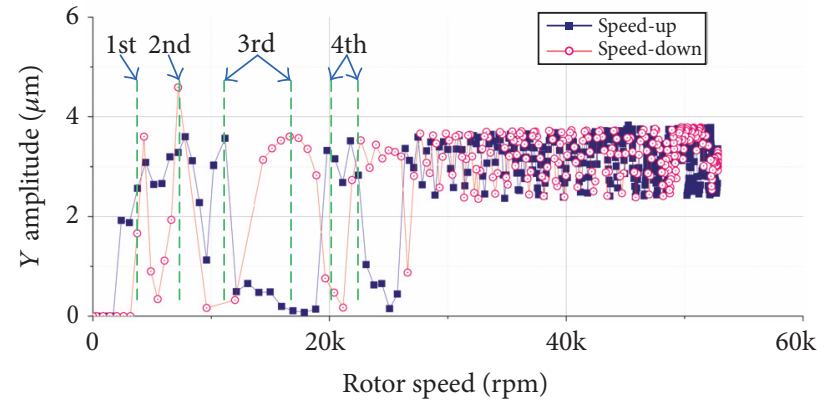

(b)

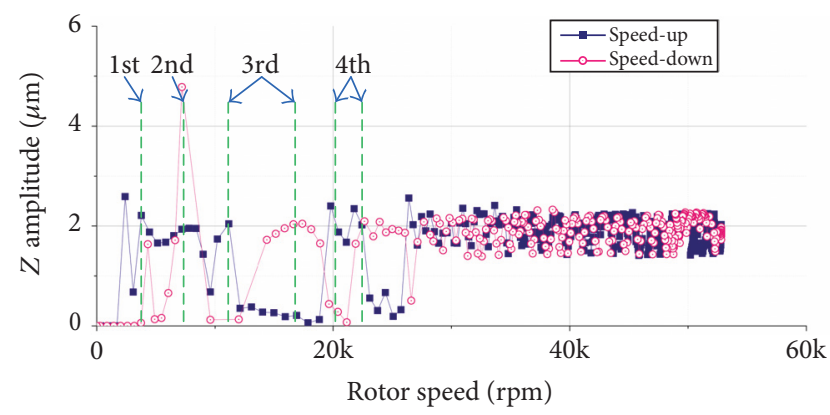

(c)

FIGURE 13: Vibration amplitude of the high speed rotor at main frequencies in the speed-up and coast-down process: (a) $X$ direction; (b) $Y$ direction; (c) $Z$ direction.

operating speed range from $10000 \mathrm{rpm}$ to $30000 \mathrm{rpm}$ after lift-off, as shown in Figure 11, the eccentricity in speed-up process is smaller than nominal clearance of $100 \mu \mathrm{m}$ and larger than the nominal clearance in speed-down process. The critical speeds of the rotor-bearing system are correlated to the supporting stiffness from bearing. With the rotor weight kept unchanged, the fluid film stiffness varies very little. Therefore, most of the supporting stiffness originates from foil supporting stiffness. In air lubrication regime, the stiffness of the foil bearing support in speed-down process is higher than that in speed-up process. These could also be attributed to the impeding effect of friction between the foils in speed-up process and speed-down process. Corresponding to the $1 \mathrm{~N}$ main frequency vibration, there are $2 \mathrm{~N}$ harmonic component vibrations with similar pattern. The vibration amplitude with 2 times the working frequency is relative smaller relative to the main frequency. There are many reasons for the $2 \mathrm{~N}$ vibrations, such as misalignment of the rotor, asymmetric stiffness of the rotor, bearing nonlinearity, aerodynamic forces [40]. In this rotor-bearing system, misalignment and bearing nonlinearity in the journal and thrust bearings are inevitable.

The rotor locus in a time interval of $0.1 \mathrm{~s}$ around $30000 \mathrm{rpm}, 40000 \mathrm{rpm}$, and $50000 \mathrm{rpm}$ is shown in Figures 14(a), 14(b), and 14(c), respectively. The trajectory of the rotor is almost of circular shape and vibration amplitude is small being within $4 \mu \mathrm{m}$ from the frequency and vibration amplitude relation. There are three vertices on the trajectory which might be attributed to the asymmetry of the foil journal bearing from leading edge to trailing edge.
The repeatability of the rotor trajectory is quite well. With increase of rotor speed, the amplitude of nonsynchronous vibration around $100 \mathrm{~Hz}$ increases and cluttered trajectory appears at around $50000 \mathrm{rpm}$. With increase of rotor speed, its amplitude increases from less than $0.5 \mu \mathrm{m}$ to around $1 \mu \mathrm{m}$. Similar to the tested results in [31], the rotor locus also becomes cluttered around $90 \mathrm{krpm}$ when the bearing clearance is larger than $80 \mu \mathrm{m}$ with protuberant foil thickness of $0.07 \mathrm{~mm}$. In this paper, the nonsynchronous vibrations are more obvious, which could be attributed to the larger nominal bearing clearance. Preload of foil journal bearing suppresses the onset of nonsynchronous vibrations due to the direct stiffening and damping effects [38]. Therefore, higher damping foil bearing might be promising solutions to the nonsynchronous whirling motion. Thus, more sophisticated foil bearing designs are anticipated to reduce both vibration amplitudes comprehensively in future application.

In rotor-bearing system, higher vibration amplitudes (radial and axial directions) might lead to catastrophic collision in the rotor-bearing system. In this study, there is no bearing failure in the whole start-up and speed-down processes with maximal operating speed up to $52000 \mathrm{rpm}$. This indicates that the compliant supporting from the protuberant foil journal and thrust bearing performed quite well in this transient process, which can be attributed to the inherited characteristics of stiffness and damping of the foils. Foil bearing with lighter compliant surface is eminent in prevention of failure. In addition, the compliant structure could dissipate a certain amount of vibration through damping, which prevents the vibration energy accumulation 

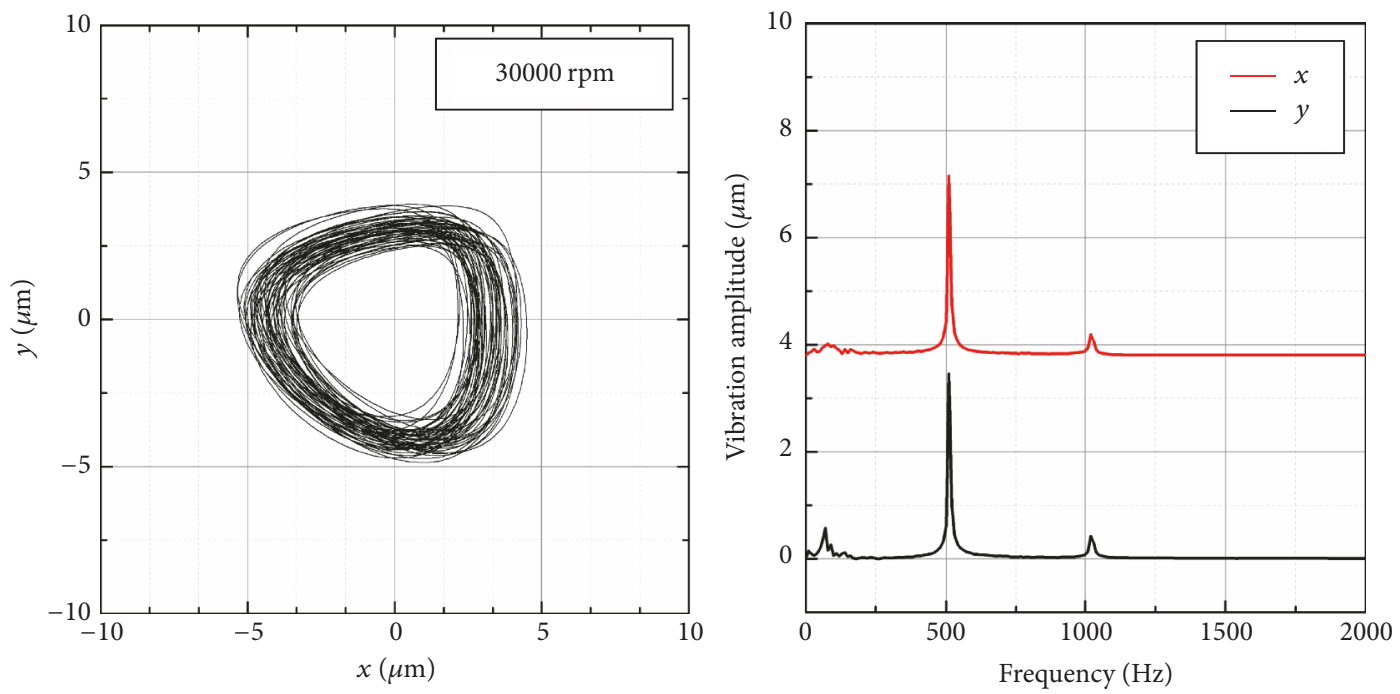

(a)
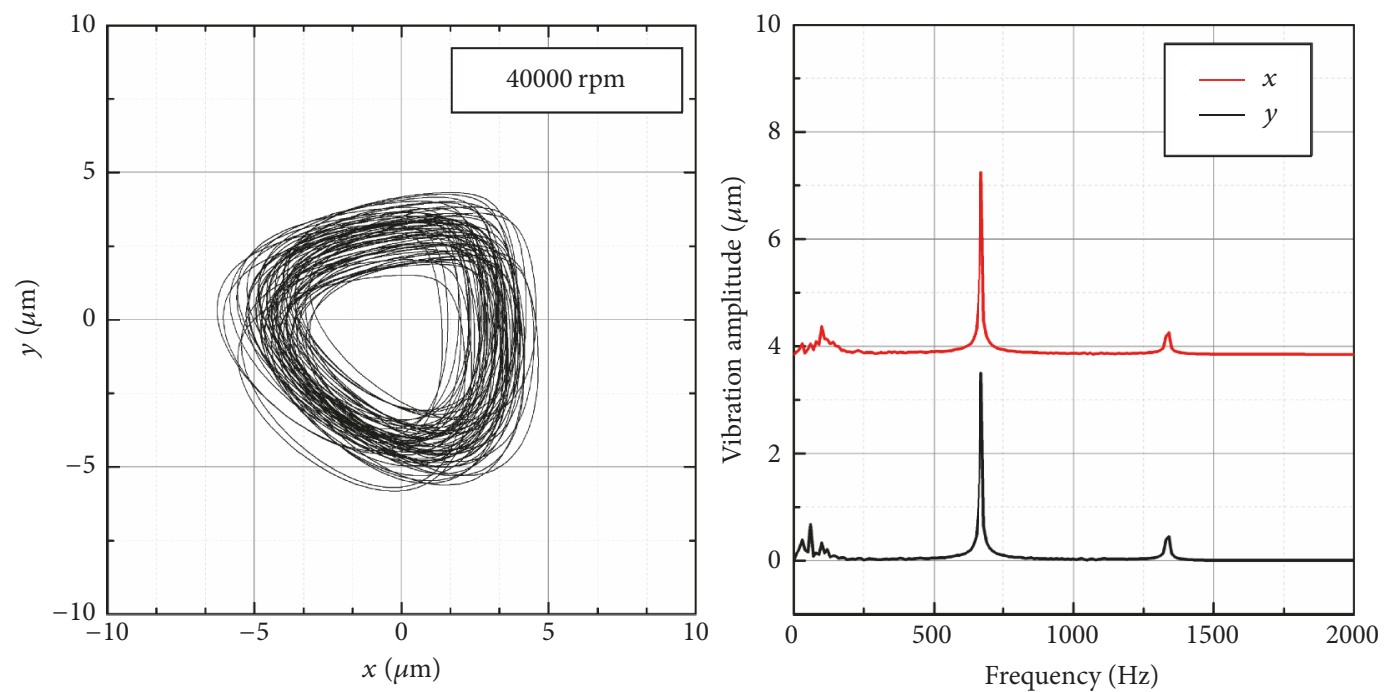

(b)
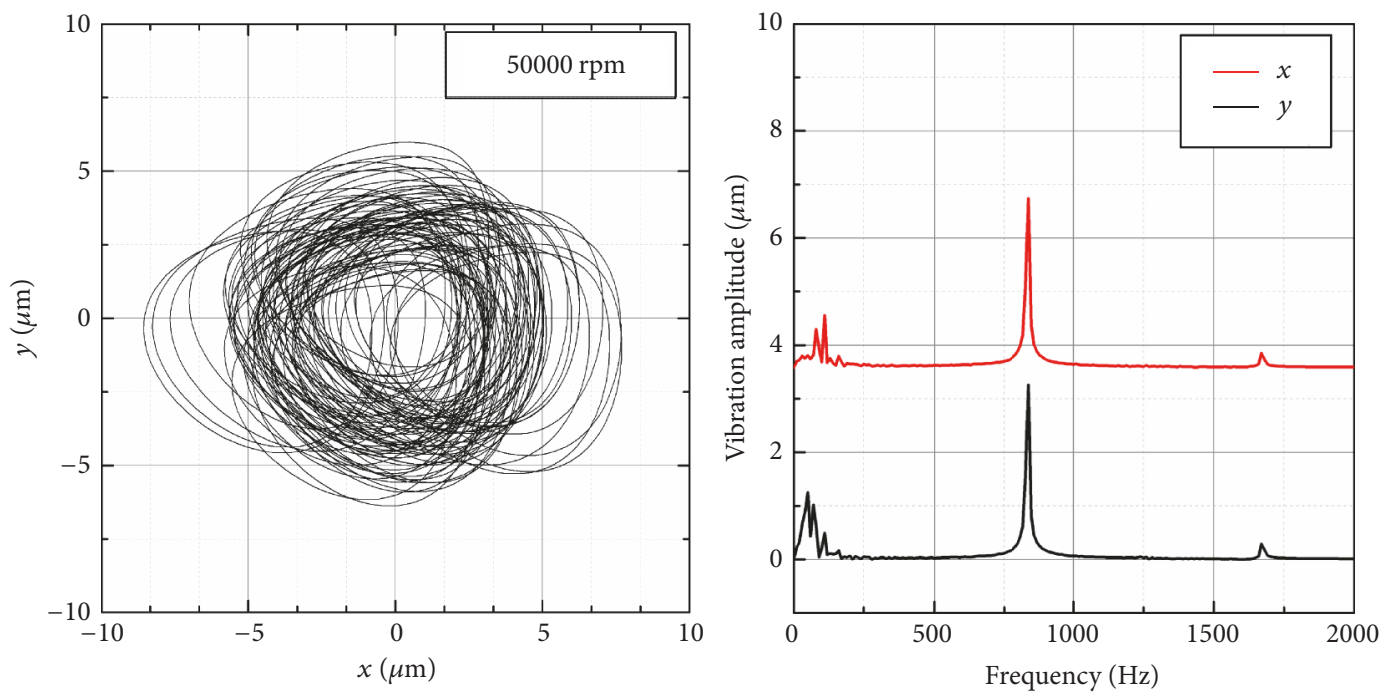

(c)

FIGURE 14: Rotor orbits and vibrations in $X$ and $Y$ directions: (a) $30000 \mathrm{rpm}$; (b) $40000 \mathrm{rpm}$; (c) $50000 \mathrm{rpm}$. 
on the rotor. For the thrust bearing, larger subsynchronous rotor lateral motions could be suppressed by increasing the bearing load [23]. In this experiment, higher speed could not be reached under higher supply pressure and unbalance force on the rotor and so on. Optionally, thrust bearing with newer configurations is recommended for the next step rotorbearing performance improvement.

\section{Conclusion and Discussion}

In this paper, foil bearing supporting technology using both protuberant foil journal and thrust bearings is developed for the turboexpander. For further simplification of the turboexpander, the dedicated aerostatic supply gas circuit is canceled out for process compactness and simplification. Experimental investigations are carried out on the rotorbearing system and the following conclusions might be drawn.

(1) Nonlinear stiffness of the protuberant foil journal bearing and thrust bearing appears due to friction effect from the foils. Integrated protuberant foil journal bearing and thrust bearing is applied in turboexpander with maximal operating speed around $52000 \mathrm{rpm}$. Due to compliance of the foils in the bearing, the rotor supported by protuberant foil journal bearings could operate under over-nominal bearing clearances.

(2) Bearing stiffness can be reflected by the critical speeds of the rotor-bearing system. During the transient speed-up and speed-down processes, the stiffness of the compliant foil journal bearing is almost the same in lower speed range. However, in higher speed range after lift-off, the supporting stiffness is higher in the speed-down process due to the stiffening effect from the friction between the foils.

(3) Axial force on the rotor originates mainly from expansion wheel in the transient speed-up and speeddown processes. Before lift-off of the rotor from the bearing, pressure at the back of expansion wheel results in the displacement of the rotor in the direction from braking wheel to expansion wheel. For further retrofitting, aerodynamic matching of the two wheels is recommended to further balancing the axial load. Alternatively, thrust bearing with newer configurations is anticipated to withstand higher axial load from the rotor.

\section{Conflicts of Interest}

The authors declared no potential conflicts of interest with respect to the research, authorship, and/or publication of this article.

\section{Acknowledgments}

This project was supported by the National Natural Science Foundation of China (51406157), Natural Science Foundation of Jiangsu Province (BK20140408), the China Postdoctoral
Science Foundation (2014M552438), and the Fundamental Research Funds for the Central Universities.

\section{References}

[1] S. Ghosh, P. Mukherjee, and S. Sarangi, "Development of bearings for a small high speed cryogenic turboexpander," Industrial Lubrication and Tribology, vol. 64, no. 1, pp. 3-10, 2012.

[2] G. L. Agrawal, "Foil air/gas bearing technology - An overview," in Proceedings of the ASME 1997 International Gas Turbine and Aeroengine Congress and Exhibition, GT '997, June 1997.

[3] T. H. Kim and L. S. Andrés, "Limits for high-speed operation of gas foil bearings," Journal of Tribology, vol. 128, no. 3, pp. 670673, 2006.

[4] J. Schiffmann and Z. S. Spakovszky, "Foil bearing design guidelines for improved stability," Journal of Tribology, vol. 135, no. 1, Article ID 011103, 2012.

[5] K. Ryu and L. S. Andrés, "On the failure of a gas foil bearing: high temperature operation without cooling flow," Journal of Engineering for Gas Turbines and Power, vol. 135, no. 11, p. 112506, 2013.

[6] Y. Hou, Z. H. Zhu, and C. Z. Chen, "Comparative test on two kinds of new compliant foil bearing for small cryogenic turboexpander," Cryogenics, vol. 44, no. 1, pp. 69-72, 2004.

[7] H. Heshmat, P. Hryniewicz, J. F. Walton II, J. P. Willis, S. Jahanmir, and C. DellaCorte, "Low-friction wear-resistant coatings for high-temperature foil bearings," Tribology International, vol. 38, no. 11-12, pp. 1059-1075, 2005.

[8] S. A. Howard, "Misalignment in gas foil journal bearings: an experimental study," Journal of Engineering for Gas Turbines and Power, vol. 131, no. 2, p. 022501, 2009.

[9] M. Branagan, D. Griffin, C. Goyne, and A. Untaroiu, "Compliant gas foil bearings and analysis tools," Journal of Engineering for Gas Turbines and Power, vol. 138, no. 5, Article ID 054001, 2015.

[10] D. Rubio and L. S. Andrés, "Bump-type foil bearing structural stiffness: experiments and predictions," Journal of Engineering for Gas Turbines and Power, vol. 128, no. 3, pp. 653-660, 2004.

[11] L. S. Andrés and T. A. Chirathadam, "Performance characteristics of metal mesh foil bearings: predictions versus measurements," Journal of Engineering for Gas Turbines and Power, vol. 135, no. 12, Article ID 122503, 2013.

[12] Q. Zhou, R. Chen, and Y. Hou, "Dynamic characteristics of viscoelastic supported air foil thrust bearing under axial whirl," Advanced Science Letters, vol. 4, no. 4-5, pp. 1552-1555, 2011.

[13] Q. Zhou, Y. Hou, and C. Chen, "Dynamic stability experiments of compliant foil thrust bearing with viscoelastic support," Tribology International, vol. 42, no. 5, pp. 662-665, 2009.

[14] L. S. Andrés, K. Ryu, and T. H. Kim, "Thermal management and rotordynamic performance of a hot rotor-gas foil bearings system-part I: measurements," Journal of Engineering for Gas Turbines and Power, vol. 133, no. 6, p. 062501, 2011.

[15] L. S. Andrés, K. Ryu, and T. H. Kim, “Thermal management and rotordynamic performance of a hot rotor-gas foil bearings system-Part II: predictions versus test data," Journal of Engineering for Gas Turbines and Power, vol. 133, no. 6, p. 062502, 2011.

[16] M. N. Pham and H.-J. Ahn, "Experimental optimization of a hybrid foil-magnetic bearing to support a flexible rotor," Mechanical Systems and Signal Processing, vol. 46, no. 2, pp. 361372, 2014. 
[17] D.-H. Lee, Y.-C. Kim, and K.-W. Kim, "The effect of Coulomb friction on the static performance of foil journal bearings," Tribology International, vol. 43, no. 5-6, pp. 1065-1072, 2010.

[18] M. Carpino and G. Talmage, "Subfoil stiffness effects in gaslubricated foil journal bearings," Tribology Transactions, vol. 51, no. 5, pp. 602-608, 2008.

[19] H. Heshmat and P. Hermel, "Compliant foil bearings technology and their application to high speed turbomachinery," Tribology and Interface Engineering Series, vol. 25, no. C, pp. 559-575, 1993.

[20] Y.-B. Lee, S. B. Kwon, T. H. Kim, and K. Sim, "Feasibility study of an oil-free turbocharger supported on gas foil bearings via on-road tests of a two-liter class diesel vehicle," Journal of Engineering for Gas Turbines and Power, vol. 135, no. 5, Article ID 052701, 2013.

[21] B. Dykas, R. Bruckner, C. DellaCorte, B. Edmonds, and J. Prahl, "Design, fabrication, and performance of foil gas thrust bearings for microturbomachinery applications," Journal of Engineering for Gas Turbines and Power, vol. 131, no. 1, Article ID 012301, 2009.

[22] D. Kim, A. S. Lee, and B. S. Choi, "Evaluation of foil bearing performance and nonlinear rotordynamics of $120 \mathrm{~kW}$ oil-free gas turbine generator," Journal of Engineering for Gas Turbines and Power, vol. 136, no. 3, Article ID 032504, 2013.

[23] T. H. Kim, Y.-B. Lee, T. Y. Kim, and K. H. Jeong, "Rotordynamic performance of an oil-free turbo blower focusing on load capacity of gas foil thrust bearings," Journal of Engineering for Gas Turbines and Power, vol. 134, no. 2, Article ID 022501, 2011.

[24] D. Kim, A. Creary, S. S. Chang, and J. H. Kim, "Mesoscale foil gas bearings for palm-sized turbomachinery: design, manufacturing, and modeling," Journal of Engineering for Gas Turbines and Power, vol. 131, no. 4, Article ID 042502, 2009.

[25] Y. Hou, S. Yang, X. Chen, S. Chen, and T. Lai, "Study on the matching performance of a low temperature reverse Brayton air refrigerator," Energy Conversion and Management, vol. 89, pp. 339-348, 2015.

[26] Y. Hou, S. Chen, R. Chen, Q. Zhang, and H. Zhao, "Numerical study on foil journal bearings with protuberant foil structure," Tribology International, vol. 44, no. 9, pp. 1061-1070, 2011.

[27] Y. Hou, T. Lai, B. Ma, Y. Zheng, and S. Chen, "Experimental investigation on the multi-decked protuberant gas foil journal bearing," Journal of Advanced Mechanical Design, Systems, and Manufacturing, vol. 7, no. 4, pp. 791-799, 2013.

[28] S. Chen, Y. Hou, L. Niu, S. Yang, and T. Lai, "Study on doublelayer protuberant gas foil journal bearings with different foil layers arrangement," Journal of Advanced Mechanical Design, Systems, and Manufacturing, vol. 9, no. 2, 2015.

[29] T. Lai, S. Chen, B. Ma, L. Liu, and Y. Hou, "Preliminary experimental study on static loading characteristics of multidecked protuberant foil thrust bearing," Journal of Advanced Mechanical Design, Systems, and Manufacturing, vol. 10, no. 1, 2016.

[30] Y. Zheng, T. Lai, S. Chen, L. Chen, L. Liu, and Y. Hou, "Static characteristics of six pads multilayer protuberant foil thrust bearings," Proceedings of the Institution of Mechanical Engineers, Part J: Journal of Engineering Tribology, vol. 231, no. 2, pp. 158164, 2016.

[31] T. Lai, S. Chen, B. Ma, Y. Zheng, and Y. Hou, "Effects of bearing clearance and supporting stiffness on performances of rotorbearing system with multi-decked protuberant gas foil journal bearing," Proceedings of the Institution of Mechanical Engineers,
Part J: Journal of Engineering Tribology, vol. 228, no. 7, pp. 780788, 2014.

[32] T. Lai, Y. Guo, W. Wang, S. Chen, and Y. Hou, "Experimental study on multi-decked protuberant foil thrust bearing with different number of thrust pads," Journal of Advanced Mechanical Design, Systems, and Manufacturing, vol. 10, no. 9, 2016.

[33] Y. Zheng, T. Lai, S. Chen, L. Chen, L. Liu, and Y. Hou, "Static characteristics of six pads multilayer protuberant foil thrust bearings," Proceedings of the Institution of Mechanical Engineers, Part J: Journal of Engineering Tribology, vol. 231, no. 2, pp. 158164, 2017.

[34] F. Balducchi, M. Arghir, R. Gauthier, and E. Renard, "Experimental analysis of the start-up torque of a mildly loaded foil thrust bearing," Journal of Tribology, vol. 135, no. 3, Article ID 031702, 2013.

[35] Y. Hao, L. Tan, Y. Liu, Y. Xu, J. Zhang, and B. Zhu, "Energy performance and radial force of a mixed-flow pump with symmetrical and unsymmetrical tip clearances," Energies, vol. 10, no. 1, article no. 57, 2017.

[36] Y. Liu, L. Tan, M. Liu, Y. Hao, and Y. Xu, "Influence of prewhirl angle and axial distance on energy performance and pressure fluctuation for a centrifugal pump with inlet guide vanes," Energies, vol. 10, no. 5, 2017.

[37] T. Lei, Z. B. Shan, C. S. Liang, W. Y. Chuan, and W. B. Bin, "Numerical simulation of unsteady cavitation flow in a centrifugal pump at off-design conditions," Proceedings of the Institution of Mechanical Engineers, Part C: Journal of Mechanical Engineering Science, vol. 228, no. 11, pp. 1994-2006, 2014.

[38] L. Tan, B. Zhu, Y. Wang, S. Cao, and S. Gui, "Numerical study on characteristics of unsteady flow in a centrifugal pump volute at partial load condition," Engineering Computations (Swansea, Wales), vol. 32, no. 6, pp. 1549-1566, 2015.

[39] K. Sim, B. Koo, J. S. Lee, and T. H. Kim, "Effects of mechanical preloads on the rotordynamic performance of a rotor supported on three-pad gas foil journal bearings," Journal of Engineering for Gas Turbines and Power, vol. 136, no. 12, Article ID 122503, 2014.

[40] M. L. Adams, Rotating Machinery Vibration: From Analysis to Trouble Shooting, CRC Press Taylor and Francis Group, New York, NY, USA, 2nd edition, 2010. 


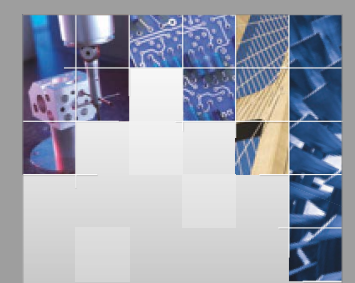

\section{Enfincering}
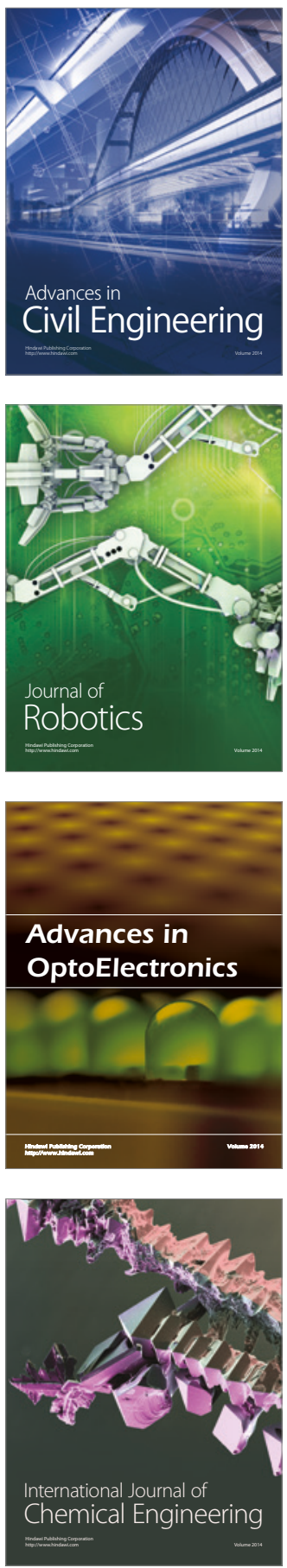

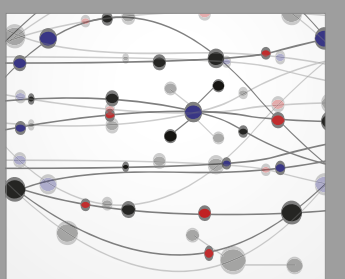

The Scientific World Journal

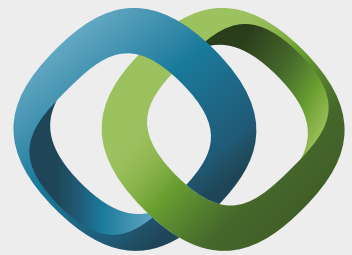

\section{Hindawi}

Submit your manuscripts at

https://www.hindawi.com
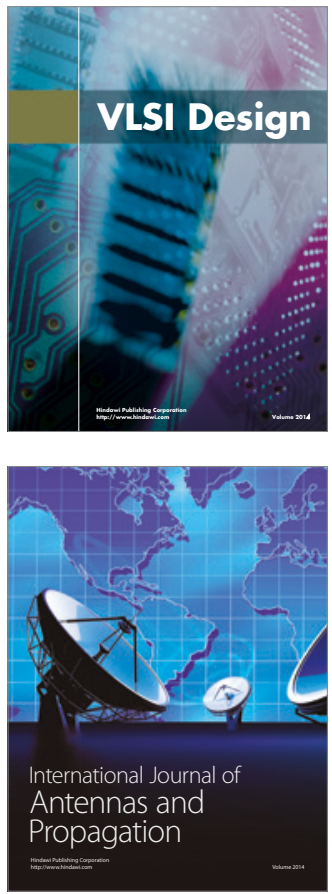

\section{Rotating}

Machinery
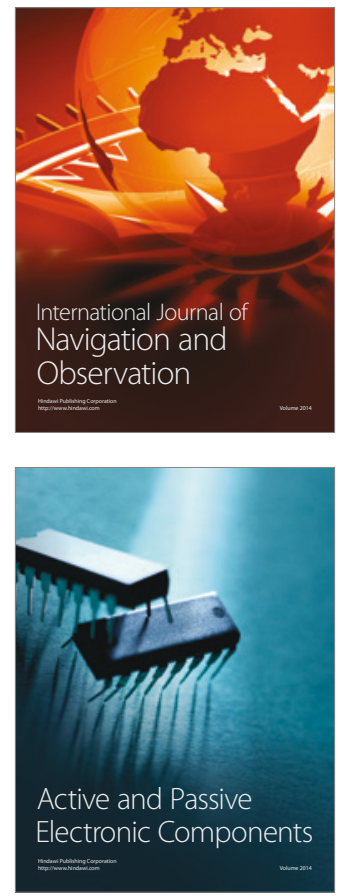
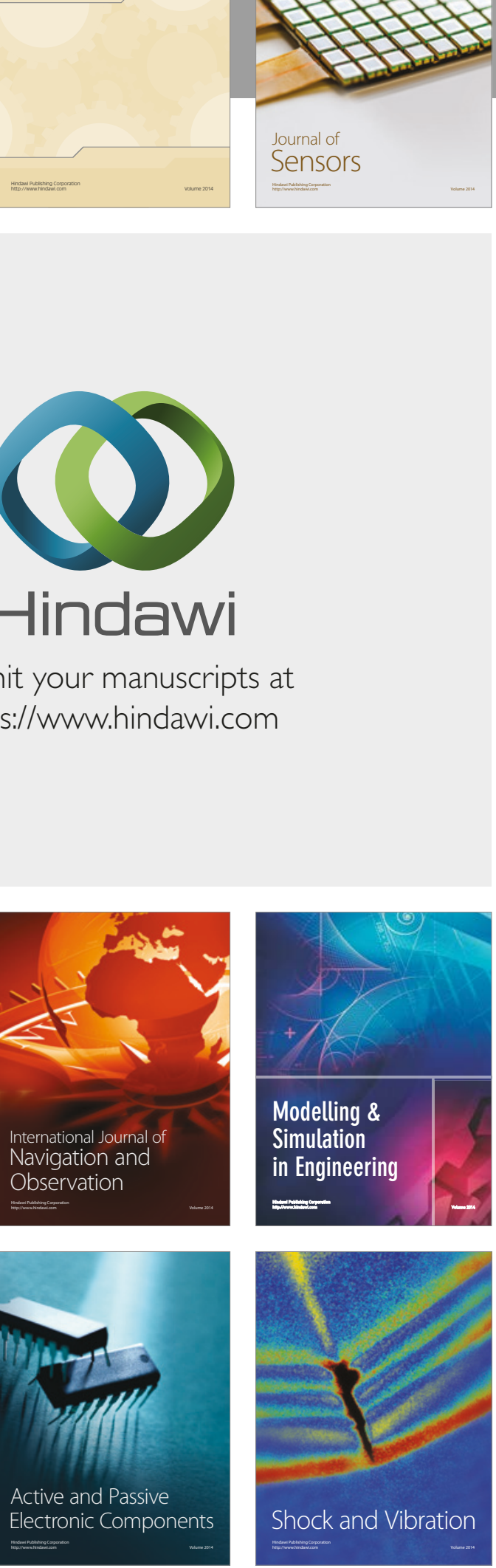
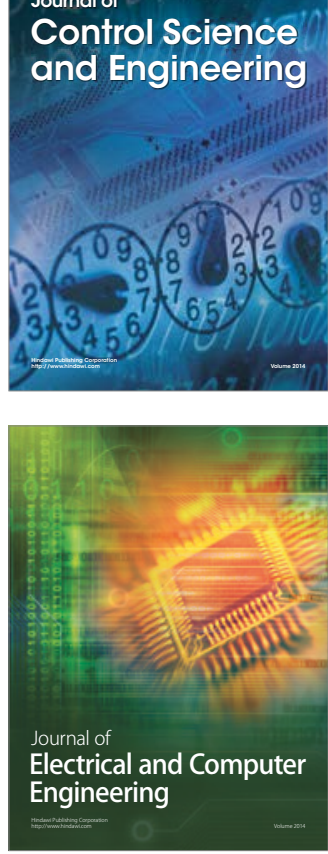

Distributed

Journal of

Control Science

and Engineering
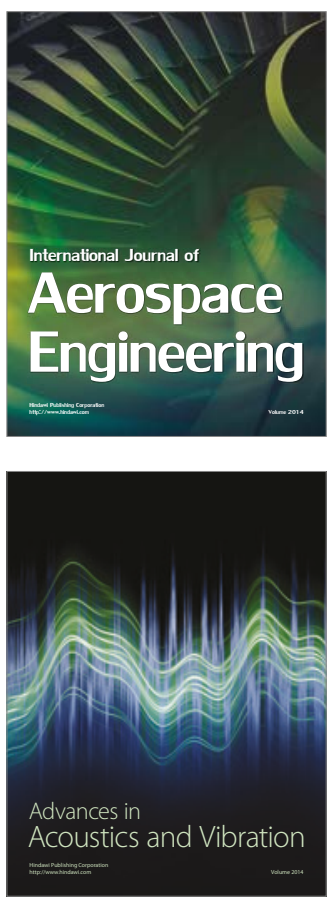

Sensor Networks 